\title{
NECROPOLÍTICA E NEOLIBERALISMO
}

\author{
Silvio Luiz de Almeida*
}

\begin{abstract}
O conceito de necropolítica introduzido no debate público por Achille Mbembe tem sido frequentemente mobilizado para a reflexão acerca das formas de violência perpetradas pelo Estado, especialmente contra as populações mais pobres e as minorias raciais. Entretanto a leitura do ensaio de Mbembe demonstra que, mais do que um desdobramento da biopolítica de Foucault - conceito que procura explicar as especificidades da dominação sob a égide do Estado moderno -, o conceito de necropolítica pretende dar conta do modo como a governamentalidade e suas tecnologias se impõem diante das mudanças na forma de reprodução social do capitalismo, no caso, as mudanças provocadas pelo neoliberalismo. Portanto pretende-se analisar como Mbembe, a partir da leitura crítica de Foucault, concebe a especificidade das formas de dominação no que considera ser a etapa neoliberal da economia capitalista.
\end{abstract}

Palavras-chave: Necropolítica. Neoliberalismo. Biopolítica. Estado. Racismo.

\section{INTRODUÇÃO}

Em 2003, Achille Mbembe publicou um ensaio de grande repercussão intitulado "Necropolítica”. A partir de uma crítica ao conceito de biopolítica introduzido por Michel Foucault, o texto propõe uma análise do exercício da soberania que confere centralidade à experiência do colonialismo e do apartheid. Diante do colonialismo e do apartheid, o exercício da soberania não pode ser descrito apenas como a manutenção do equilíbrio entre a vida e a morte, ao "fazer viver e deixar morrer". Neste contexto, o poder soberano se manifesta fundamentalmente por mecanismos de produção sistemática da morte como a guerra, o homicídio e o suicídio, ou seja, como necropolítica.

Entretanto a necropolítica se refere a um modo do exercício da soberania que não se limita às circunstâncias específicas do colonialismo e do apartheid. Em obras posteriores, como Crítica da razão negra, de 2013, e Políti-

* Fundação Getúlio Vargas.

Avenida Nove de Julho, 2029 - Bela Vista. Cep: 01313-902. São Paulo - São Paulo -Brasil. silviovlq@gmail.com https://orcid.org/0000-0003-0990-9707 cas da inimizade, de 2016, o colonialismo e o apartheid não são tratados mais como meras circunstâncias, mas como formas de dominação que transcendem os países e os períodos históricos em que essas experiências ocorreram. Dito de outro modo, colonialismo e apartheid geraram modelos de administração e tecnologias de gestão cujo funcionamento se caracteriza pela produção sistemática da morte.

Para estabelecer a diferença entre a biopolítica descrita por Foucault e o que denomina de necropolítica, Mbembe se vale de dois outros conceitos: estado de exceção e estado de sítio. "O estado de exceção e a relação de inimizade tornaram-se a base normativa do direito de matar", e que funciona com apelo à "exceção, à emergência e a uma noção ficcional do inimigo" (Mbembe, [2003] 2018a, p. 17), que precisam ser constantemente repetidas nas práticas políticas.

O que para Mbembe torna insuficiente o conceito de biopolítica? É essa questão que este artigo se propõe a perseguir. O artigo parte da hipótese de que a insuficiência apontada por Mbembe repousa no argumento de que o conceito de biopolítica não englobaria todas 
as dimensões que a ascensão do neoliberalismo provocou no exercício da soberania, em especial a expansão da lógica colonial e as transformações do racismo, no que denominou de "universalização da condição negra" (Mbembe, [2013] 2018b). Em Mbembe, o neoliberalismo implica em uma forma de governamentalidade, que só pode ser adequadamente descrita com o aporte dos conceitos de estado de exceção e estado de sítio, além de uma nova formulação do que Foucault chamou de racismo de Estado.

Portanto o artigo seguirá o seguinte caminho: a) reconstituir o conceito de governamentalidade tal como apresentado por Michel Foucault; b) reconstituir o conceito de racismo de Estado; c) mostrar como a questão do neoliberalismo aparece na obra de Mbembe e como ele o relaciona com o conceito de necropolítica.

No caso de Michel Foucault, a análise do conceito de biopolítica, governamentalidade e racismo de Estado será feita tendo como fontes principais os textos "Segurança, território, população" ([1978] 2008a), "Nascimento da Biopolítica" ([1976] 1999) e "Em defesa da sociedade” ([1979] 2008b). Já em relação aos conceitos trabalhados por Mbembe, servirão como referência os textos "Necropolítica" (2018a), "Crítica da razão negra" (2018b) e "Políticas da inimizade” ([2016] 2020).

\section{BIOPOLÍTICA E GOVERNAMENTA-} LIDADE

O conceito de biopolítica foi sendo paulatinamente apresentado no interior dos trabalhos de Foucault, de forma que não se permite determinar facilmente (Lemke, 2018). Afirma Thomas Lemke (2018) que a definição de biopolítica se encontra muito mais no fato de tornar visível "a distinção (contingente e precária) entre política e vida, cultura e natureza, entre o tangível e o intangível, e o dado de modo inquestionado, de um lado, e a ação responsabilizada moral e juridicamente, de outro" (p. 49).
O que Foucault demonstra é que as fronteiras entre natureza e política, aparentemente estáveis, "são menos ponto de partida do que efeito da ação política” (Lemke, 2018, p. 50). A biopolítica é o conceito que permite apreender o processo histórico a partir do qual a vida emerge como resultado das práticas de poder.

A trajetória do conceito começa em 1974, quando, pela primeira vez, é utilizado na conferência "A verdade e as formas jurídicas". A partir de História da sexualidade: a vontade de saber, de 1976, o conceito se firma no universo conceitual foucaultiano. Mas é nos cursos "Em defesa da sociedade", de 1975/1976, "Segurança, território e população”, de 1977/1978 e "Nascimento da biopolítica", de 1978/1979, que o conceito de biopolítica passará ao status de categoria analítica fundamental. Das mencionadas conferências destacaremos dois elementos fundamentais para a definição do conceito governamentalidade e racismo de Estado.

No que consiste a biopolítica? Foucault propõe uma mudança na ideia de governo que implica em pensar o exercício do poder não sobre um Estado, um território ou uma estrutura política. O governo é sempre sobre as pessoas, homens, indivíduos ou coletividades. Para Foucault (2008a, p. 164), "os homens é que são governados”. O exercício do governo é identificado com as diversas estratégias, métodos e tecnologias para controle dos indivíduos, agora tomados como população. A partir de tais pressupostos, Foucault empreenderá a análise das mudanças nas formas de governo ocorridas especialmente a partir do século XVIII, com a constituição dos Estados orientados pelo liberalismo. Entre os séculos XVII e XVIII, mais do que um conjunto de ideias sobre o governo, o liberalismo corresponde à instauração de um conjunto de práticas governamentais ajustadas às exigências da sociabilidade capitalista. Esse conjunto de práticas Foucault denomina de governamentalidade (Foucault, 2008a, p. 138).

A governamentalidade pode ser definida como: a) "o conjunto constituído pelas 
instituições, os procedimentos, análises e reflexões, os cálculos e as táticas que permitem exercer um tipo complexo e específico de poder" e que "tem por alvo principal a população, por principal forma de saber a economia política e por instrumento técnico essencial os dispositivos de segurança"; b) o "governo", entendido como um poder que se sobrepõe a todos os outros como "soberania e disciplina", e que se manifesta por meio de uma série de "aparelhos específicos de governo" e pelo "desenvolvimento de toda uma série de saberes"; c) o processo histórico que resultou na formação, a partir dos século XVII, do "Estado administrativo" ou, em outros termos, o Estado "racional" é "governamentalizado" (Foucault, 2008a, p. 143-144).

A análise de Foucault afasta-se de especulações sobre uma suposta "natureza" ou "essência” do Estado da qual poderiam ser deduzidas todas as suas estruturas e funções. Se o Estado for entendido como uma espécie de "universal político", Foucault (2008b, p. 105) afirma renunciar a uma "teoria do Estado" que veja as coisas desta forma. O que lhe interessa é "a identificação da estatização progressiva, certamente fragmentada, mas contínua, de certo número de práticas, de maneiras de fazer e, se quiserem, de governamentalidades" (Foucault, 2008b, p. 105). Assim, os problemas da doença mental, da medicina clínica e da constituição das práticas disciplinares no sistema penal são resultados de uma cada vez maior "estatização" ou, em outros termos, de um conjunto de múltiplas práticas de poder, de disciplina e de regimes de saber (Foucault, 2008b). O Estado deve ser tomado como "o efeito móvel de um regime de governamentalidades múltiplas" (Foucault, 2008b, p. 105).

Governamentalidade se refere à "razão governamental" ou aos "tipos de racionalidade que são postos em ação nos procedimentos pelos quais a conduta dos homens é conduzida por meio de uma administração estatal" (Foucault, 2008b, p. 432). Mas como Foucault analisa o neoliberalismo a partir do conceito de governamentalidade? Qual a relação de neoliberalismo com governamentalidade? Talvez seja importante dizer, inicialmente, que o neoliberalismo não se restringe a uma série de políticas econômicas e nem a uma ideologia (Andrade, 2019; Brown, 2019; Dardot; Laval, [2013] 2009). Ainda que o neoliberalismo também se manifeste na forma de políticas econômicas e de discurso ideológicos, o neoliberalismo é processo de constituição da subjetividade e, consequentemente, de novos sentidos para a vida e para morte, uma biopolítica, portanto. E, como biopolítica, o neoliberalismo corresponde a um conjunto específico de práticas de governo orientadas por uma peculiar e circunstanciada razão de Estado. Cabe sempre lembrar que, ao falarmos de práticas de governo no modo proposto por Foucault (2008b), estamos nos referindo a um "regime de governamentalidades múltiplas" e, assim, à "estatização".

O Estado no neoliberalismo não é um Estado "limitado" ou "ausente", mas que se caracteriza por estabelecer novas formas de intervenção ou, nos termos foucaultianos, "relações de dominação e técnicas de sujeição polimorfas" (Foucault, 1998, p. 182). Apesar de frisar que o neoliberalismo alemão e o neoliberalismo americano guardem diferenças significativas entre si, ${ }^{1}$ Foucault (2008b) mostra que há ao menos três pontos em comum entre essas experiências históricas: a) a crítica ao pensamento de Keynes; b) a repulsa ao intervencionismo estatal na forma do planejamento e, especialmente, à planificação; c) a circulação de toda uma série de pessoas, personagens, teorias e livros, especialmente os ligados à chamada escola austríaca (Foucault, 2008b, p. 107).

${ }^{1}$ Foucault (2008b) ressalta que as distinções entre o neoliberalismo alemão e o neoliberalismo americano podem também ser encontradas em suas diferentes "ancoragens históricas". No caso alemão, Foucault vê a ancoragem nos eventos da República de Weimar, na crise de 1929 e no desenvolvimento do nazismo, na crítica do nazismo e, enfim, na reconstrução do pós-guerra. Já no caso americano, a ancoragem está na crítica da política do New Deal e nas críticas ao intervencionismo federal do pós-guerra implantados pelas administrações democratas. 


\section{ESTADO, GUERRA E RACISMO}

O segundo conceito que tornará possível a compreensão da crítica de Mbembe à ideia foucaultiana de biopolítica é racismo de Estado. Antes de tudo, cabe notar que em Foucault (1999) o exame das relações de poder requer o abandono do modelo jurídico da soberania, que olha para o poder sob o ângulo da legitimidade do Estado. Em vez de perguntar como os sujeitos concedem legitimidade a um poder ao qual irão se sujeitar, a investigação deveria se debruçar sobre "como as relações de sujeição podem fabricar sujeitos". Desse modo, a investigação por ele proposta se volta à compreensão da maneira como "relações de força que se entrecruzam, remetem umas às outras, convergem ou, ao contrário, se opõem e tendem a anular-se" (Foucault, 1999, p. 319).

Nesse ponto em que as relações de força são apresentadas como a materialização do poder é que a questão da guerra ganha importância fundamental na reflexão sobre o Estado. Foucault estabelece a guerra como "um analisador das relações de força” (Foucault, 1999, p. 320). O que marca o Estado contemporâneo é o fato de que guerra não é um momento, mas uma permanência. A guerra, portanto, é a forma assumida pelas relações de poder nas sociedades capitalistas em que os conflitos de classe, os antagonismos sociais e a concorrência são partes integrantes da vida social (Hirs今 ch, 2010; Mascaro, 2013). Como afirma Fou- cault “a guerra é a cifra da paz”, uma vez que

divide permanentemente o corpo social inteiro; coloca cada um de nós num campo ou no outro. E essa guerra, não basta encontrá-la como um princípio de explicação; é preciso reativá-la, fazê-la deixar as formas latentes e surdas em que ela prossegue sem que a percebamos bem e levá-la a uma batalha decisiva para a qual devemos preparar-nos, se quisermos ser vencedores (Foucault, 1999, p. 322).

Não se faz referência, aqui, a uma guerra presente, mas à instituição de uma lógica de guerra cuja importância está em ativar o uso das tecnologias e dos dispositivos de poder.
É sob a lógica da guerra que o Estado se apresenta no século XIX como o "protetor da integridade, da superioridade e da pureza da raça” (Foucault, 1999, p. 95). A noção de pureza das raças é a expressão da face antirrevolucionária, conservadora e reacionária que o discurso político assume após as revoluções liberais do século XVIII (Foucault, 1999). O racismo "é, literalmente, o discurso revolucionário, mas pelo avesso", uma vez que o exercício da soberania terá como objetivo a "proteção da raça” (Foucault, 1999, p. 95). A isso Foucault denomina de "racismo de Estado". A integridade do Estado se apoia na divisão social criada pelo racismo.

A partir do século XIX, a soberania deixa de ser o poder de tirar a vida e passa a ser o poder de mantê-la e prolongá-la, de fazer viver e deixar morrer. O biopoder é cada vez mais "disciplinar e regulamentador" (Foucault, 1999, p. 304). Todavia o racismo permite o exercício da função da morte em um sistema político centrado no biopoder (Foucault, 1999, p. 304-305), de tal sorte que é possível dizer que "quase não há funcionamento moderno do Estado que, em certo momento, em certo limite e em certas condições, não passe pelo racismo" (Foucault, 1999, p. 304). São duas as funções do racismo de Estado. A primeira é garantir a divisão no contínuo biológico da espécie humana, introduzindo hierarquias, distinções, classificações de raças que permitam determinar diferentes valores à vida humana, a depender do grupo social ao qual pertençam (Foucault, 1999, p. 304). A segunda é estabelecer uma relação positiva com a morte do Outro. É nesse ponto que a guerra, tal como mencionamos acima, se torna tão importante. O biopoder funda uma relação de tipo biológico em que o Outro não precisa morrer porque ameaça a minha vida e o grupo ao qual pertenço; o Outro precisa morrer porque é um degenerado, da "raça ruim" que ameaça o livre, sadio, vigoroso e desimpedido desenvolvimento da minha espécie (Foucault, 1999, p. 304). É desse modo que o racismo é "a condição de 
aceitabilidade de tirar a vida numa sociedade de normalização" (Foucault, 1999, p. 305).

É dessa forma que o racismo, desde o advento da modernidade, se torna "indispensável como condição para poder tirar a vida de alguém, para poder tirar a vida dos outros", de tal sorte que "a função assassina do Estado só pode ser assegurada, desde que o Estado funcione no modo do biopoder, pelo racismo" (Foucault, 1999, p. 304). É assim que, conforme ressalta Foucault (1999, p. 308), "a guerra vai se mostrar, no final do século XIX, como uma maneira não simplesmente de fortalecer a própria raça eliminando a raça adversa (conforme os temas da seleção e da luta pela vida), mas igualmente de regenerar a própria raça”. A soberania estatal sob a égide do biopoder, que pressupõe o exercício do poder de matar e de classificar a vida, "implica o funcionamento, a introdução e a ativação do racismo" (Foucault, 1999, p. 309).

\section{RACISMO E NECROPOLÍTICA}

Recai sobre a sociedade nazista e o Estado nazista, consoante Foucault (1999), a responsabilidade por algo "extraordinário": a generalização do biopoder. O nazismo teria realizado a fusão primordial entre o direito soberano de matar, típico das sociedades pré-modernas, com os novos mecanismos do biopoder. Para Foucault (1999, p. 311), o Estado nazista "tornou absolutamente coextensivos o campo de uma vida que ele organiza, protege, garante, cultiva biologicamente, e, ao mesmo tempo, o direito soberano de matar quem quer que seja - não só os outros, mas os seus próprios”. Há, a um só tempo, "um Estado absolutamente racista, um Estado absolutamente assassino e um Estado absolutamente suicida" (Foucault, 1999, p. 311).

A peculiaridade do Estado nazista - ao mesmo tempo assassino e suicida - é que sua existência não se define apenas pelo propósito de destruir outras raças, mas pela exposição "de sua própria raça ao perigo absoluto e uni- versal da morte”. É a exposição à morte que completa o delírio nazista da superioridade da raça diante de outras que devem ser "totalmente exterminadas" ou ser "definitivamente sujeitadas” (Foucault, 1999, p. 310). Mas há uma observação feita por Foucault (1999) que merece nossa atenção, tendo em vista os propósitos deste artigo. A destruição de outras raças e da própria raça - a "solução final" - embora abertamente assumida pelo nazismo, é uma possibilidade porque essa contradição mortal já está inscrita no modo de funcionamento de todo e qualquer Estado e se apresenta na forma do inafastável do jogo que coloca frente a frente o direito soberano de matar e os mecanismos do biopoder (Foucault,1999).

É neste ponto que Mbembe encaixa sua crítica ao conceito de biopolítica. As tendências racistas, assassinas e suicidas do Estado encontram no nazismo o seu ponto mais visível dentro do território europeu, mas não tem origem na Europa. Mbembe, tal como já fizera Aimé Césaire ([1950] 2020), lembra que é o colonialismo a origem de tais tendências. O colonialismo é o lugar em que a governamentalidade se apresenta como o exercício permanente e sistemático da morte. O que aponta Mbembe (2018a, 2018b) é que as formas de governamentalidade e de racismo de Estado têm a experiência colonial em sua gênese. O nazismo é, no máximo, a fratura exposta que coloca a um só golpe o direito de matar e a biopolítica na constituição dos Estados modernos. Mas, na radiografia dos Estados modernos, o que aparece é a ossatura do colonialismo e do apartheid.

O colonialismo e o apartheid estabelecem uma governamentalidade irredutível ao "fazer viver e deixar morrer" da biopolítica. Trata-se, aqui, do necropoder e da necropolítica, em que a guerra, a política, o homicídio e o suicídio são as formas de exercício da soberania. As diferenças entre a biopolítica e a necropolítica são demarcadas por Mbembe com o apelo ao conceito de estado de exceção (Agamben, 2003; Mbembe, 2018a, 2018b; Schmitt, [1922] 1992). Para Mbembe (2018a, 
p. 19), “o estado de exceção e a relação de inimizade tornaram-se a base normativa do direito de matar", que se vale de um apelo permanente à "exceção, à emergência e a uma noção ficcional do inimigo”. Foi na experiência colonial que se estabeleceu de forma originária a síntese entre "massacre e burocracia" (Mbembe, 2018a, p. 32) que originou a criação de políticas de governo baseadas na seleção de raças, na proibição de casamentos mistos, na esterilização forçada e até mesmo o extermínio dos povos vencidos, práticas que, como sabemos, transcenderam o território das colônias e fazem parte até mesmo das ditas democracias liberais. (Mbembe, 2018a Pires, 2021).

Mais do que a lógica da guerra e da formação do inimigo externo e interno que irá garantir a integridade do Estado, a necropolítica tem como base o terror, herança direta do colonialismo e do apartheid. O terror impõe a absoluta alteridade, em que a soberania "consiste fundamentalmente no exercício de um poder à margem da lei - ab legibus solutus - e no qual tipicamente a 'paz' assume a face de uma 'guerra sem fim”' (Mbembe, 2018a, p. 32). $\mathrm{O}$ necropoder se manifesta neste espaço em que a legalidade não chega, em que o poder de matar, e não a racionalidade da norma, anuncia a existência do Estado (Mbembe, 2018a). É o território da ocupação colonial, onde a soberania se manifesta em um lugar identificado com desordem, loucura, "zona de fronteira”, onde o สี inimigo está sempre à espreita e onde, mesmo N que não haja guerra, há a permanente ameaça de guerra. Vale lembrar que a guerra, elemento que compóe o Estado moderno segundo Foucault, é regulado pelo direito internacional, ¿. pelo direito de guerra. A guerra legítima "é, em ङ grande medida, uma guerra conduzida por um $\therefore$ Estado contra outro ou, mais precisamente, uma guerra entre "Estados civilizados" (Mbembe, 2018a, p. 34). O Estado é o modelo de unidade política, "um princípio de organização racional, a personificação da ideia universal e um símbolo de moralidade”, daí sua centralidade no cálculo da guerra (Mbembe, 2018a, p. 34).
O que notabiliza o contexto colonial é a permanente ameaça da guerra, e não a guerra em si. Se a guerra não foi política e juridicamente declarada, não há limites a observar. Mas a ameaça de guerra faz nascer a emergência que justifica a exceção. Abre-se espaço às medidas preventivas, à antecipação ao inimigo que se impõe na forma de ocupação territorial e suspensão das garantias constitucionais (como o estado de sítio e o estado de exceção). O estado de guerra sem guerra é uma "formação de terror" que corresponde à "concatenação do biopoder, o estado de exceção e o estado de sítio" (Mbembe, 2018, p. 31).

\section{NECROPOLÍTICA E NEOLIBERA- LISMO}

Em Crítica da razão negra e Políticas de inimizade, Mbembe irá tratar do que considera uma "reintrodução global da relação colonial" (Mbembe, [2016] 2020, p. 14-15), uma relação de guerra, guerras de conquista e de ocupação, mas também guerras de sitiamento, de intrusão e guerras raciais. E essa reintrodução se dá no contexto do neoliberalismo. Mas o que Mbembe entende por neoliberalismo, afinal? Em Crítica da razão negra é interessante notar que a definição de neoliberalismo aparece no ponto em que são descritos os momentos de criação do que Mbembe (2018b, p. 10) denomina de "vertiginoso conjunto", ou seja, do negro e da raça. A associação negro/raça é o resultado do colonialismo que sempre se atualiza no contexto das transformações ocorridas nas sociedades contemporâneas. O neoliberalismo criou uma associação específica entre negro e raça, diferente da existente nas etapas anteriores do capitalismo. Enfim, para que se compreenda como o racismo se manifesta contemporaneamente é preciso levar em conta o processo de globalização dos mercados, da privatização do mundo e da crescente complexificação da economia financeira, do complexo militar pós-imperial e das tecnologias eletrôni- 
cas e digitais (Mbembe, 2018b). Mas o contrário também pode ser afirmado: a compreensão do neoliberalismo passa a considerar o racismo um elemento analítico crucial.

O neoliberalismo é definido por Mbembe (2018b, p. 15) como "uma fase da história da humanidade dominada pelas indústrias do silício e pelas tecnologias digitais" e que se caracteriza por três elementos: a) o tempo curto em que a força reprodutiva é convertida na forma dinheiro, e no qual em todos os âmbitos e situações se pode atribuir um valor de mercado; b) a produção da indiferença, que se caracteriza pela "paranoica codificação da vida social tanto em normas, categorias e números, quanto por diversas operações de abstração que pretendem racionalizar o mundo a partir de lógicas empresariais"; c) a ausência de limites, tanto de fins quanto de meios, ao capital financeiro.

Mbembe descreve os efeitos do neoliberalismo na constituição dos sujeitos do seguinte modo: a) Surgimento de nômades do trabaIho, em que a tragédia da multidão não é mais a exploração, pois "não poder ser explorada de modo nenhum, é ser relegada a uma "humanidade supérflua" e "sem qualquer utilidade para o funcionamento do capital” (Mbembe, 2018b, p. 15). b) Surgimento de uma nova forma de vida psíquica "apoiada na memória artificial e digital e em modelos cognitivos provenientes das neurociências e da neuroeconomia”. Com isso tem-se a criação de automatismos psíquicos e tecnológicos que consolidam a ficção de "um novo sujeito humano, empreendedor de si mesmo, moldável e convocado a se reconfigurar permanentemente em função dos artefatos que a época oferece". Mbembe chama esse "novo homem" de "sujeito do mercado e da dívida, vê-se a si mesmo como um mero produto do acaso" (Mbembe, 2018b, p. 16). c) Aprisionamento no desejo e reconstrução da vida íntima como mercadoria. O que marca esse efeito é a distinção entre o sujeito da sociedade industrial e o sujeito neoliberal. Se o primeiro é "trágico" e "alienado", o segundo é um prisioneiro do próprio desejo, cujo gozo não mais repousa no consumo, mas "depende quase inteiramente da capacidade de reconstruir publicamente sua vida íntima e de oferecê-la no mercado como uma mercadoria passível de troca". Esse "sujeito neuroeconômico," cuja vida psíquica e política se orienta pelas normas de mercado, está "condenado à aprendizagem por toda a vida, à flexibilidade e ao reino do curto-prazo; deve abraçar sua condição de sujeito solúvel e fungível, a fim de atender à injunção que lhe é constantemente feita - tornar-se um outro" (Mbembe, 2018b, p. 16). d) Fusão capitalismo e animismo. Esse efeito está diretamente relacionado à importância que Mbembe confere ao racismo na descrição do neoliberalismo. Para o autor, o neoliberalismo representa "a época na qual o capitalismo e o animismo, durante muito tempo obrigados a se manterem afastados, tendem finalmente a se fundir" (Mbembe, 2018b, p. 16). A modernidade operou uma separação entre razão e desejo, sujeito e objeto e ser e dever-ser, a fim de conter as energias pulsionais. Nem tudo poderia ser reificado, transformado em objeto de cálculo e, consequentemente, em mercadoria. Algumas fantasias e desejos deveriam ser sublimados em nome de um determinado projeto civilizador (Mbembe, 2018b, p. 16).

Porém o neoliberalismo é a era em que "entram em colapso os diques de contenção das pulsões" (Mbembe, 2020, p. 194-195) construídos pela sociedade industrial. A distinção entre pessoa humana, animal ou máquina já não é tão certa, assim como também não há certeza sobre se a fabricação de espécies e subespécies de seres humanos continua sendo um tabu consubstanciado, por exemplo, no sistema internacional de proteção aos direitos humanos.

Por fim, chegamos a um dos pontos centrais da descrição do neoliberalismo feita por Achille Mbembe. Trata-se da universalização da condição negra ou devir negro no mundo (Mbembe, 2018b). O neoliberalismo escancara o colonialismo como governamentalidade e a plantation como tecnologia de poder que se apresenta mesmo após as lutas de libertação e 
os processos de descolonização jurídica e política (Fanon, [1964] 1980, [1952] 2020; Mbembe, [2010] 2019). Se nos períodos anteriores do capitalismo apenas os negros escravizados estavam expostos a certos riscos, o neoliberalismo "democratizou" tais riscos, estendendo a condição negra para toda a humanidade. A lógica colonial de captura, predação, ocupação e exploração tornou-se a forma de administração das sociedades contemporâneas, atravessadas pelas exigências objetivas e subjetivas da reprodução econômica da etapa neoliberal (Mbembe, 2018b).

O racismo no período neoliberal ganha novos contornos, torna-se "espetáculo" e "parte dos dispositivos pulsionais e da subjetividade econômica". O racismo é "mais um produto de consumo da mesma categoria que outros bens, objetos e mercadorias" (Mbembe, 2020, p. 105) nas prateleiras de uma economia da atenção e que se move por estímulos pulsionais. Para Mbembe (2020, p. 105), "nesta época dominada pela paixão pelo lucro, essa combinação de luxúria, brutalidade e sensualidade favorece o processo de assimilação do racismo pela 'sociedade do espetáculo' e sua molecularização pelos dispositivos do consumo contemporâneo". É assim que o racismo "alimenta nossa necessidade de diversão e nos permite escapar ao tédio reinante e à monotonia", fenômeno a que Mbembe chama de nanorracismo. O nanorracismo é o "direito de rir às custas خิ daquele que se busca estigmatizar" e que for๙ nece o "prazer em chafurdar na ignorância" e S reivindicar "o direito à estupidez e à violência nela fundadas” (p. 105). que parece estar condensada ao zoneamento e à expulsão" (Mbembe, 2020, p. 196). Esse devir negro no mundo, essa expansão global da condição negra coincide com a transformação do capitalismo em "uma forma de religião animista" e, por consequência, do ser humano em "homem-fluxo, digital, infiltrado de todos os lados pelos mais variados órgãos sintéticos e próteses artificias" (Mbembe, 2020, p. 196). O "negro de fundo" é o inimigo, é o Outro do neoliberalismo. É contra os perigos deste "negro de fundo", essa personificação da humanidade decaída que se fará a unidade política e se instituirá o dispositivo militar e de segurança na sociedade da inimizade.

\section{CONCLUSÃO}

Ainda que o conceito de necropolítica seja articulado como uma crítica ao conceito de biopolítica, isso não deve ser entendido como oposição, mas como apontamento de limites, extensão e continuidade. Mbembe aponta as insuficiências teóricas da biopolítica para tratar das mutações sofridas nas relações de poder, especialmente na etapa neoliberal do capitalismo. As insuficiências estariam em dois pontos específicos. O primeiro, na ausência de uma reflexão de Foucault sobre o impacto do colonialismo na constituição dos dispositivos de sujeição e de dominação presentes em todas as sociedades contemporâneas, mesmo as liberais e democráticas. Em segundo lugar, a falta de uma reflexão mais profunda sobre as especificidades do racismo em conexão com as diferentes formas de governamentalidade. Para Mbembe, o neoliberalismo inaugura uma etapa em que a categorização da humanidade em raças superiores e inferiores para fins do exercício do poder de matar não depende mais de uma ligação direta com o imaginário socialmente produzido acerca dos negros de origem africana. O racismo é não apenas parte fundamental das práticas de governo e do exercício da soberania, mas também o proces- 
so de constituição de um tipo de subjetividade própria do neoliberalismo. Em outras palavras, o racismo ganha contornos próprios no neoliberalismo, etapa do capitalismo em que como em nenhum momento experimentou-se a fusão entre mercadoria, desejo e morte.

Tanto para Mbembe como para Foucault, o neoliberalismo, mais do que política econômica e ideologia, é um processo histórico de constituição da subjetividade que resulta de múltiplas formas de exercício do poder. Por isso, a raça e o racismo são elementos sem os quais não se pode compreender a governamentalidade neoliberal. A governamentalidade neoliberal é a necropolítica, um necroliberalismo (Mbembe, 2020). A necropolítica é a forma de exercício da soberania que se funda na expansão da lógica colonial, tendo em vista que a reprodução das condições objetivas e subjetivas da vida econômica se estabelece com a constante depreciação da vida material, com o aprisionamento do desejo na forma de mercadoria e com a financeirização de todos os âmbitos da vida. Se no neoliberalismo a condição para o exercício da soberania é a constante reinvindicação do direito de matar, o negro - esse sujeito gestado para a morte no leito do colonialismo se afirma como a referência da forma universal do sujeito no neoliberalismo.

Recebido para publicação em 13 de julho de 2021 Aceito em 26 de setembro de 2021

\section{REFERÊNCIAS}

AGAMBEN, G. Estado de exceção. São Paulo: Boitempo, 2003

ANDRADE, D. P. O que é o neoliberalismo? A renovação do debate nas ciências sociais. Sociedade e Estado, [s. l.], v. 34, n. 1, p. 211-239, 2019.

BROWN, W. Nas ruínas do neoliberalismo. São Paulo: Politeia, 2019.

CÉSAIRE, A. Discurso sobre o colonialismo. $1^{\text {a }}$ edição [1950]. São Paulo: Veneta, 2020.

DARDOT, P.; LAVAL, C. A nova razão do mundo: ensaio sobre a sociedade neoliberal. $1^{\mathrm{a}}$ edição [2013]. São Paulo: Boitempo, 2016.

FANON, F. Em defesa da revolução africana. $1^{\mathrm{a}}$ edição [1964]. Lisboa: Livraria Sá da Costa, 1980.

Pele negra, máscaras brancas. $1^{\mathrm{a}}$ edição [1952]. São Paulo: Ubu, 2020.

FOUCAULT, M. Em defesa da sociedade. $1^{\mathrm{a}}$ edição [1976]. São Paulo: Martins Fontes, 1999

Segurança, território, população. $1^{\mathrm{a}}$ edição [1978]. São Paulo: Martins Fontes, 2008a.

. Nascimento da biopolítica. $1^{\mathrm{a}}$ edição [1979]. São Paulo: Martins Fontes, 2008b. A verdade e as formas jurídicas. $1^{\mathrm{a}}$ edição [1974]. São Paulo: Nau, 2013.

História da sexualidade: a vontade de saber. 1ª edição [1976]. Rio de Janeiro: Paz e Terra, 2014. V. 1.

HIRSCH, J. Teoria materialista do Estado. São Paulo: Renovar, 2010.

LEMKE, T. Biopolítica: críticas, debates, perspectivas. São Paulo: Politeia, 2018

MASCARO, A. Estado e forma política. São Paulo: Boitempo, 2013.

MBEMBE, A. Necropolítica. $1^{\text {a }}$ edição [2003]. São Paulo: $\mathrm{N}-1,2018 \mathrm{a}$.

. Crítica da razão negra. $1^{\text {a }}$ edição [2013]. São Paulo: $\overline{\mathrm{N}-1,2018 \mathrm{~b}}$

Sair da grande noite: ensaio sobre a África descolonizada. $1^{\mathrm{a}}$ edição [2010]. São Paulo: Petrópolis: Vozes, 2019.

Pandemia democratizou o poder de matar, diz autor da teoria da necropolítica. Entrevista concedida a Diogo Bercito. Folha de São Paulo, São Paulo, 30 mar. 2020. Disponível em: https://www1.folha.uol.com.br/ mundo/2020/03/pandemia-democratizou-poder-de-matardiz-autor-da-teoria-da-necropolitica.shtml. Acesso em: 12 jun. 2021. N-1, 2020

Políticas da inimizade. $1^{\mathrm{a}}$ edição [2016]. São Paulo:

PIRES, L. M. Estados de exceção: a usurpação da soberania popular. São Paulo: Contracorrente, 2021.

SCHMITT, C. Teologia política. $1^{\text {a }}$ edição [1922]. Belo Horizonte: Del Rey, 1992 


\section{NECROPOLITICS AND NEOLIBERALISM}

\author{
Silvio Luiz de Almeida
}

The concept of necropolitics introduced into public debate by Achille Mbembe has been increasingly mobilized to reflect on the forms of violence perpetrated by the State, especially against the poor population and the racial minorities. However, reading Mbembe's essay demonstrates that more than an unfolding of Foucault's biopolitics concept - which seeks to explain the specifics of the domination carried out under the aegis of the Modern State -, the idea of necropolitics intends to account for the form with which governmentality and its technologies impose themselves in the face of changes in the way of social reproduction of capitalism, in this case, the changes caused by neoliberalism. Therefore, this text intended to analyze how Mbembe, based on Foucault's critical reading, conceives the specificity of forms of domination in what he considers to be the neoliberal stage of the capitalist economy.

Keywords: Necropolitics. Neoliberalism. Biopolitics. State. Racism.

\section{NÉCROPOLITIQUE ET NÉOLIBÉRALISME}

\author{
Silvio Luiz de Almeida
}

Le concept de nécropolitique introduit par Achille Mbembe dans le débat public est souvent utilisé pour réfléchir à propos des formes de violence fait par l'État, spécialement à la population plus pauvre et les minorités raciales. Pourtant, la lecture de l'essai de Mbembe montre que, en plus qu'un déroulement de la biopolitique de Foucault - un concept qui cherche à expliquer les spécificités de la domination sous la égide de l'État moderne -, le concept de nécropolitique a l'intention de rendre compte de la façon dont la gouvernmentalité et ses technologies s'imposent face à les changements dans la façon de reproduction sociale du capitalisme, dans ce cas, les changements causés par le néolibéralisme. Ainsi, ce texte a l'intention d'analiser comment Mbembe, basé sur une lecture critique de Foucault, conçoit les spécificités des formes de domination dans celle qu'il considère la phase néolibéraliste du capitalisme.

Mots-CLÉs: Nécropolitique. Néolibéralisme. Biopolitique. État. Racisme.

Silvio Luiz de Almeida - Doutor em Direito pelo Departamento de Filosofia e Teoria Geral do Direito da Faculdade de Direito da Universidade de São Paulo (Largo São Francisco). Mestre em Direito Político e Econômico e bacharel em Direito pela Faculdade de Direito da Universidade Presbiteriana Mackenzie. Graduado em Filosofia pela Faculdade de Filosofia, Letras e Ciências Humanas da Universidade de São Paulo. Concluiu o pós-doutorado pela Faculdade de Direito da Universidade de São Paulo. Foi Mellon Visiting professor do Center for Latin American and Caribbean Studies (CLACS) da Universidade de Duke (EUA) em 2020. É autor dos livros Racismo estrutural, Sartre: direito e política e O direito no jovem Lukács: a filosofia do direito em história e consciência. Preside o Instituto Luiz Gama. 